\title{
All-Solid-State Textile Batteries Made from Nano-Emulsion Conducting Polymer Inks for Wearable Electronics
}

\section{Di Wei *, Darryl Cotton and Tapani Ryhänen}

Nokia Research Centre, Broers Building, 21 JJ Thomson Av., CB3 0FA, Cambridge, UK;

E-Mails: daryl.cotton@nokia.com (D.C.); tapani.ryhanen@nokia.com (T.R.)

* Author to whom correspondence should be addressed; E-Mail: di.wei@nokia.com;

Tel.: +44-782-687-1586.

Received: 17 July 2012; in revised form: 23 July 2012 / Accepted: 1 August 2012 /

Published: 13 August 2012

\begin{abstract}
A rollable and all-solid-state textile lithium battery based on fabric matrix and polymer electrolyte that allows flexibility and fast-charging capability is reported. When immerged into poly(3,4-ethylenedioxythiophene) (PEDOT) nano-emulsion inks, an insulating fabric is converted into a conductive battery electrode for a fully solid state lithium battery with the highest specific energy capacity of $68 \mathrm{mAh} / \mathrm{g}$. This is superior to most of the solid-state conducting polymer primary and/or secondary batteries reported. The bending radius of such a textile battery is less than $1.5 \mathrm{~mm}$ while lightening up an LED. This new material combination and inherent flexibility is well suited to provide an energy source for future wearable and woven electronics.
\end{abstract}

Keywords: polymer battery; all-solid-state textile battery; PEDOT; conducting polymer; nano-emulsion ink

\section{Introduction}

Lithium ion batteries have been used in almost all mobile devices including PDAs, laptops and mobile phones. Development of organic displays and flexible OLEDs show promise in enabling a device which can be bent or twisted. However, these new form factors also require a pliable battery with a high specific energy capacity. Current lithium ion battery electrodes are made by coating lithium metal oxide slurries onto charge collectors. This method is not suitable in applications that require mechanical flexibility, due to the brittle nature of slurry coatings when bent or stretched. 
A lot of work has been made on developing stretchable conducting yarns [1] and textile electrodes for supercapacitors [2-4]. The basic strategy is to apply a coating of carbon nanotube $(\mathrm{CNT}) / \mathrm{MnO}_{2}$ solutions onto cotton textiles as electrodes. It is generally not easy to reproduce/control the uniformity of CNT coating and the potential toxicity of CNTs [5] also limits their application in wearable electronics. On the other hand, conducting polymers have been explored as electrodes for both supercapacitors [6,7] and batteries [8], but one of their main limitations lies in the poor adhesion to the charge collecting metal foils when used in batteries. In this paper, a cost-effective and binder-free method is developed by coating high-surface area, flexible and stretchable textiles with conducting polymer nano-emulsion inks. The polymer nano-emulsion inks can be quickly soaked into the textile matrix and directly used as cathodes in rechargeable lithium batteries.

Conducting polymers, also known as conjugated polymers including polyaniline, polypyrole, polythiophene etc., consist of alternating single and double bonds to create an extended $\pi$-network [9]. Conductivity of such polymers falls in the range of semiconductors, and some of them can be made as conducting as metals when doped by photochemical, chemical or electrochemical methods [10]. Lithium batteries can be made from various conducting polymers. All-solid-state Li/polyaniline batteries offered specific energy of $50 \mathrm{Wh} / \mathrm{kg}$ [11]. Specific energies in range of 40-60 Wh/ $\mathrm{kg}$ have been predicted for packed Li/polypyrrole cells with optimized design. When a poly(ethylene oxide) (PEO) polymer electrolyte was used, the specific energy of an all-solid-state Li/polypyrrole battery was reported to be $55 \mathrm{Wh} / \mathrm{kg}$ [12]. Among these conducting polymers a derivative of polythiophene, poly(3,4-ethylenedioxythiophene) (PEDOT) had been generally used as the charge collecting layers in organic electronics [13]. Especially when it is used in organic photovoltaics, charge collection efficiency, photocurrent efficiency and device performance were enhanced significantly. Such enhancing effect of PEDOT may be partially due to a better Ohmic contact with the lithium metal.

\section{Results and Discussion}

In our experiments, strong and durable polyester/cellulose hydroentangled nonwoven fabric cloth embedded with PEDOT nano-emulsion inks was used as a battery cathode material. The textile is exceptionally absorbent in terms of weight-to-capacity ratio and works very well as a scaffold for conducting polymer (PEDOT) nano-emulsion inks. Figure 1a shows the intrinsic polyester/cellulose fabric and Figure $1 \mathrm{~b}$ shows PEDOT soaked textile material. The conductive textile was prepared by pipetting PEDOT nano-emulsion inks onto the textile and baking at $100{ }^{\circ} \mathrm{C}$ for $2 \mathrm{~h}$. The sheet resistance of the textile was measured with a RCHEK 4-point meter before and after soaking and confirmed it changes from insulator to a conductor with a sheet resistance of approximately $160 \mathrm{Ohm} / \mathrm{sq}$. This is comparable with the electrochemical deposited polypyrrole $(171 \mathrm{Ohm} / \mathrm{sq})$ [14]. The embedded PEDOT functions both as charge collector and electro-active material in our battery design.

The original fabric (Figure 1a) is intrinsically insulating, thus only the morphology of the conducting fabric soaked with PEDOT (Figure 1b) was characterized with a scanning electron microscope (SEM, FEI/Philips XL30) in high vacuum mode $\left(3.5 \times 10^{-6} \mathrm{mbar}\right)$. Figure 1c shows that the PEDOT is coated evenly on the fibres of the polyester/cellulose textile. Diameters of such tangled spaghetti textile fibers range from 10 to $20 \mu \mathrm{m}$. 
Figure 1. Picture of (a) polyester/cellulose fabric; (b) poly(3,4-ethylenedioxythiophene) (PEDOT) soaked polyester/cellulose fabric as textile battery electrodes and (c) scanning electron microscope (SEM) images of the soaked textile.

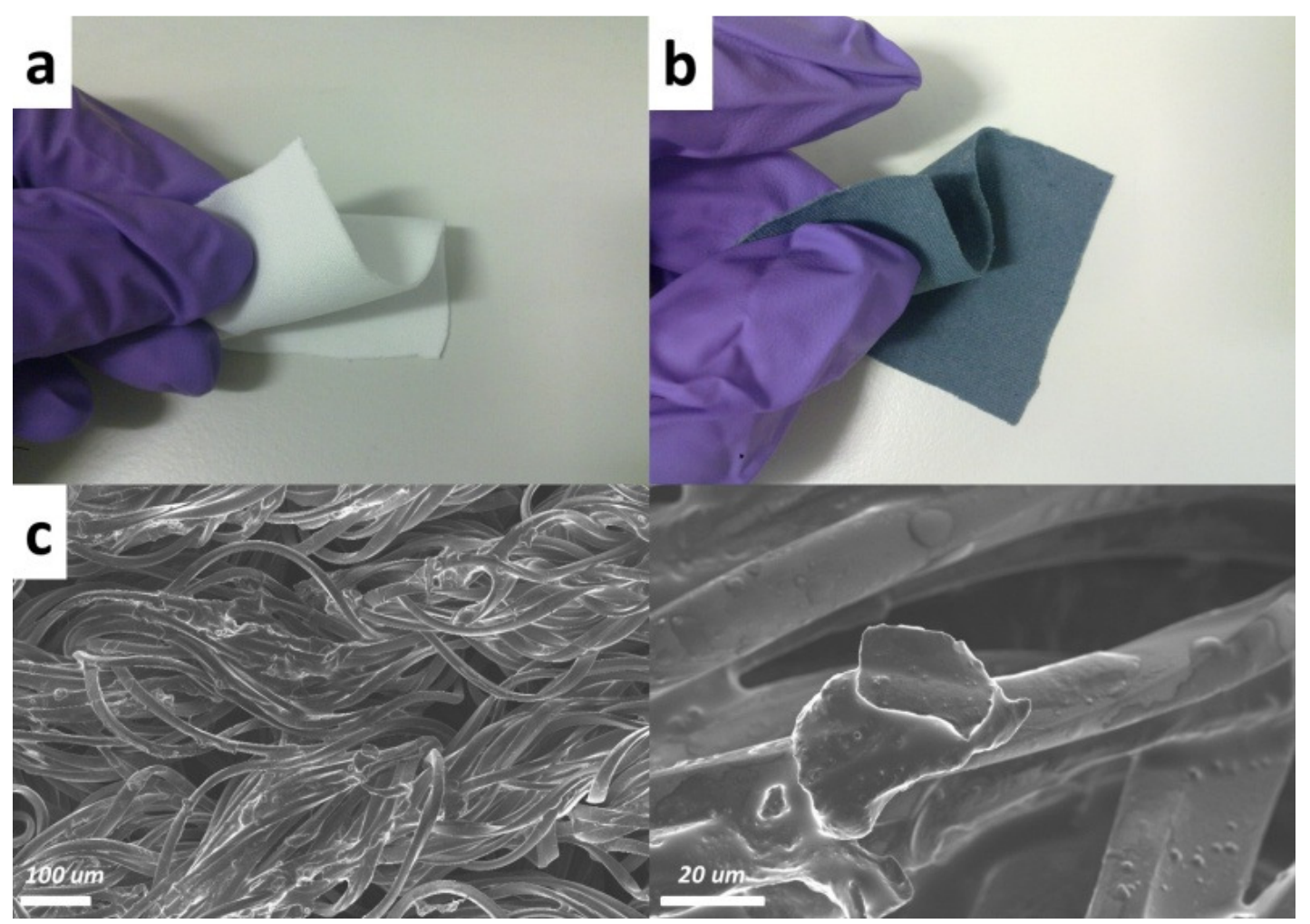

The textile batteries were constructed from a solid polymer electrolyte sandwiched between a lithium foil anode and PEDOT textile cathode as illustrated in Figure 2a. The polymer electrolyte was composed of high molecular weight poly(ethylene glycol) borate ester [15]. Performance of such polymer electrolytes is comparable with conventional liquid organic electrolytes at room temperature. To make it more flexible the separator/ polymer electrolyte can either be a fabric separator as reported in reference [4] or a stretchable gel polymer electrolyte based on monovalent acrylate polymer matrices [16]. Open circuit voltage of such a textile battery based on PEDOT is over $2.8 \mathrm{~V}$, in contrast, voltages of the batteries based on other conducting polymers such as polypyrrole are around $1 \mathrm{~V}$ [14,17]. Thus a reliable, flexible and rollable battery from PEDOT soaked textile can be used to light up an LED due to its high open circuit voltage, even with bending radius smaller than $1.5 \mathrm{~mm}$. Figure $2 \mathrm{~b}$ shows the battery wrapped around a spatula with a radius of $<1.5 \mathrm{~mm}$ and the whole textile battery can also be totally wrapped up into a roll in operation. It should also be noticed that such battery is still in full operation after 100 times bending test.

To study further electrochemical properties of this type of battery a standard 2032 coin cell was also assembled inside an mBraun glovebox $\left(\mathrm{H}_{2} \mathrm{O}<2 \mathrm{ppm}, \mathrm{O}_{2}<10 \mathrm{ppm}\right)$. The coin cell was configured in the same manner as shown in Figure 2a, where the PEDOT textile is used as the cathode, the lithium foil as an anode and poly(ethylene glycol) borate ester is the polymer electrolyte. The coin cell was discharged with a Maccor battery tester at different current densities ranging from of $10 \mathrm{~mA} / \mathrm{g}(1 / 6 \mathrm{C})$ to $240 \mathrm{~mA} / \mathrm{g}$ (4 C). Figure 3 shows the galvanostatic discharge/charge voltage profile of such coin cell with the textile PEDOT electrode. 
Figure 2. (a) Structure of the textile battery and (b) flexible and fully rollable batteries made from PEDOT soaked textile that can light up an LED.
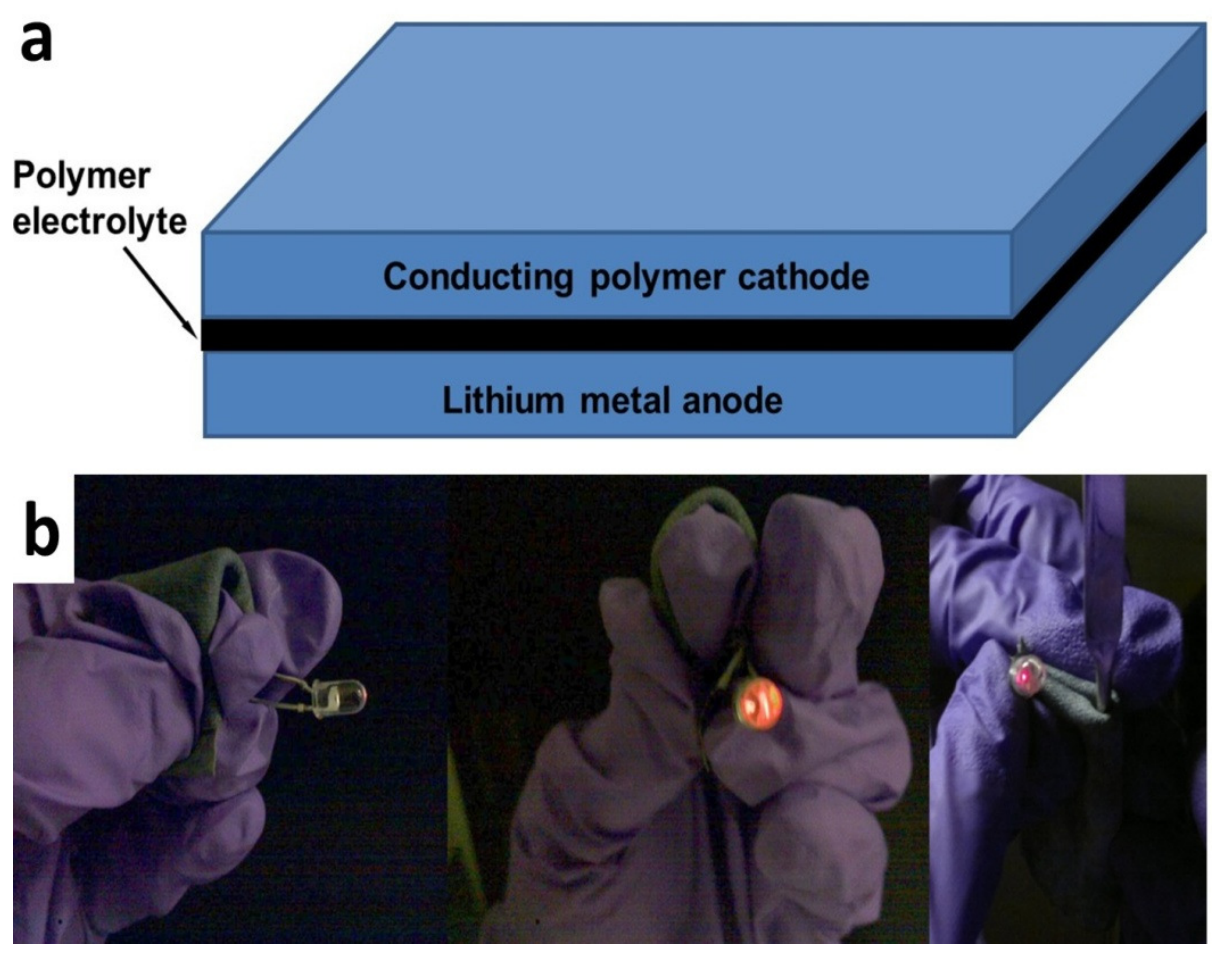

Figure 3. Galvanostatic discharge/charge curves of the textile battery at $1 / 6 \mathrm{C}$ between 0 and $3 \mathrm{~V}$ in coin cell set up. The change of specific capacities with cycle numbers is plotted in the right inset of the voltage profile.

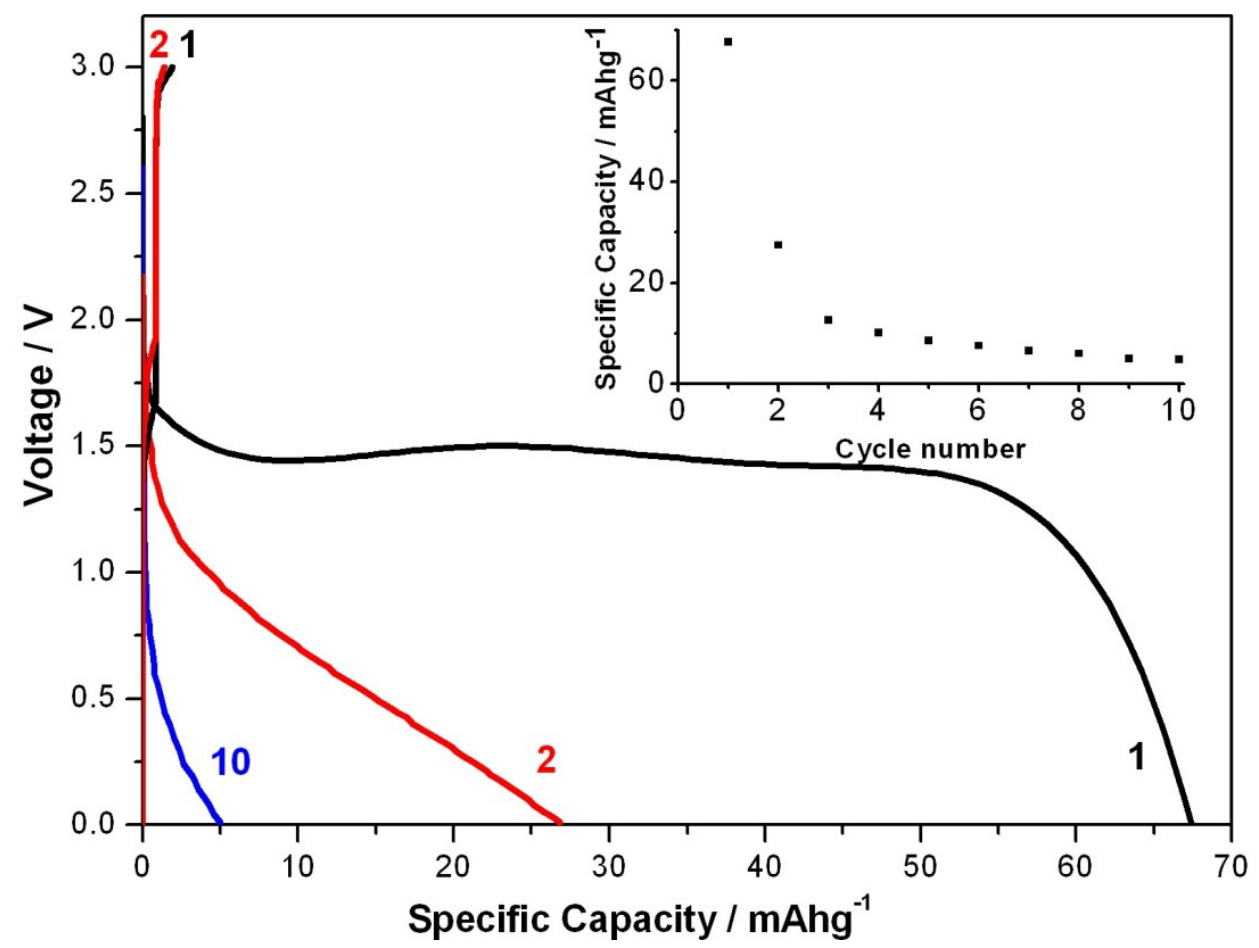

The cell was firstly cycled at $1 / 6 \mathrm{C}$ for 10 cycles. The $1 \mathrm{st}$, 2 nd and 10 th cycle of discharging curves are shown in Figure 3. Specific capacity for all-solid-state Li/polythiophene is about $44 \mathrm{mAh} / \mathrm{g}$ [18]. 
Batteries based on cellulose and polypyrrole exhibited charge capacities between 38 and $50 \mathrm{mAh} / \mathrm{g}$ per weight of the active material [17], which was the highest charge capacity reported for all conducting polymer based batteries. In contrast, the energy capacity for our textile PEDOT battery is $68 \mathrm{mAh} / \mathrm{g}$ during the first discharge, which is higher than the highest value reported to date for all-solid conducting polymer batteries. During the first discharging process the voltage reaches a plateau at about $1.5 \mathrm{~V}$. Specific capacity decreased to about $27 \mathrm{mAh} / \mathrm{g}$ during the second discharge and was stabilized at about $5 \mathrm{mAh} / \mathrm{g}$ at the 10th cycle. Change of specific capacity was shown in the insert in Figure 3. Even though the energy capacity decreases during discharging, the initial discharge capacity is the highest of its kind for primary PEDOT batteries. It should also be noticed that the battery is very quickly recharged and it only took about $7 \mathrm{~min}$ to be fully charged at $1 / 6 \mathrm{C}$. Different charging rates have been tried. When discharged with $4 \mathrm{C}$, the charging time was decrease further from 7 min (at 1/6 C) to about $16 \mathrm{~s}$. These results are in good agreement with the fast-charging ability of batteries based on conducting polymers [16].

The specific energy of lithium ion batteries is typically on the order of $10-300 \mathrm{Wh} / \mathrm{kg}$, but the specific power is only on the order of $1-100 \mathrm{~W} / \mathrm{kg}$. The typical specific energy and power of supercapacitors are in the order of $0.01-1 \mathrm{Wh} / \mathrm{kg}$ and $10-1000 \mathrm{~W} / \mathrm{kg}$, respectively. These specific values of supercapacitors are not high enough to replace batteries in many applications. A Ragone plot of the textile battery is shown in Figure 4 with the operating ranges of fuel cells, lithium batteries and super capacitors outlined. When the battery was discharged at $1 / 6 \mathrm{C}$, it behaves like a typical lithium battery, and the highest specific energy density was $91 \mathrm{Wh} / \mathrm{kg}$ as shown in Figure 4a. However, if the discharge current was increased to $4 \mathrm{C}$, it behaves like atypical supercapacitor with highest specific power density of $100 \mathrm{~W} / \mathrm{kg}$. Depending on the discharging current, this device can be used both as a battery and a supercapacitor.

Figure 4. Ragone plots of the textile batteries when discharged at (a) $1 / 6 \mathrm{C}$ and (b) $4 \mathrm{C}$ when using the PEDOT textile battery as a primary battery.

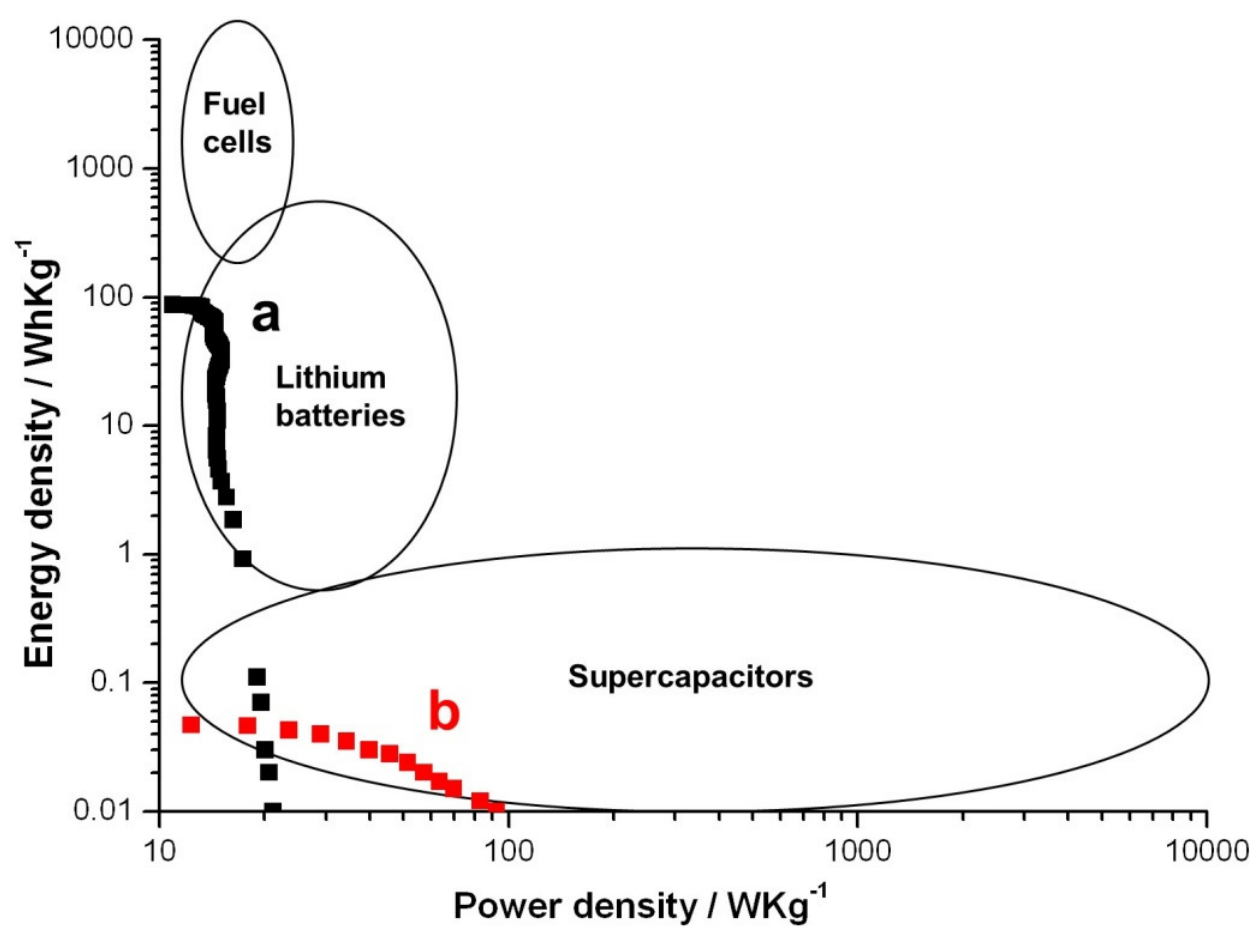




\section{Experimental Section}

The polyester/cellulose hydroentangled nonwoven fabric, "Contec amplitude EcoCloth" was purchased from Fisher Ltd and lithium metal foil was purchased from SigmaAldrich Ltd. Highly conductive PEDOT:PSS nano-emulsion ink, which can be directly used in printing applications was supplied by DKSH Ltd.

Standard 2032 coin cell was assembled inside an mBraun glovebox filled with inert Ar gas. The electrochemical properties of the assembled coin cell were studied with a Maccor battery tester.

\section{Conclusions}

In conclusion, by impetrating high-surface area textiles with nano-emulsion conducting polymer inks, we solved the challenge of loose contact and adhesion problems when applying conducting polymers in batteries. It converts the insulating textile fabric to conductive electrode of a lithium battery with the highest specific energy capacity of $68 \mathrm{mAh} / \mathrm{g}$, which is superior to most of the solid-state conducting polymer primary and secondary batteries reported. Reliable, flexible and rollable textile batteries can be made by this method and are suitable for wearable/woven electronics. Such a battery can be quickly recharged in $7 \mathrm{~min}$ at $1 / 6 \mathrm{C}$ and in $16 \mathrm{~s}$ at $4 \mathrm{C}$. This battery also enables a new and desirable portfolio of textile products which could be used as both decoration accessories and energy sources at the same time, for example, a heart rate/blood pressure monitor with textile power supplies for conformable clothing, or a phone sock made from textile batteries to charge mobile devices wirelessly.

\section{References}

1. Shim, B.S.; Chen, W.; Doty, C.; Xu, C.; Kotov, N.A. Smart electronic yarns and wearable fabrics for human biomonitoring made by carbon nanotube coating with polyelectrolytes. Nano Lett. 2008, 8, 4151-4157.

2. Hu, L.; Chen, W.; Xie, X.; Liu, N.; Yang, Y.; Wu, H.; Yao, Y.; Pasta, M.; Alshareef, H.N.; Cui, Y. Symmetrical $\mathrm{MnO}_{2}$-carbon nanotube-textile nanostructures for wearable pseudocapacitors with high mass loading. ACS Nano 2011, 5, 8904-8913.

3. Yu, G.; Hu, L.; Vosgueritchian, M.; Wang, H.; Xie, X.; McDonough, J.R.; Cui, X.; Cui, Y.; Bao, Z. Solution-processed graphene/ $\mathrm{MnO}_{2}$ nanostructured textiles for high-performance electrochemical capacitors. Nano Lett. 2011, 11, 2905-2911.

4. Hu, L.; Pasta, M.; Mantia, F.L.; Cui, L.; Jeong, S.; Deshazer, H.D.; Choi, J.W.; Han, S.M.; Cui, Y. Stretchable, porous, and conductive energy textiles. Nano Lett. 2010, 10, 708-714.

5. Poland, C.A.; Duffin, R.; Kinloch, I.; Maynard, A.; Wallace, W.A.H.; Seaton, A.; Stone, V.; Brown, S.; MacNee, W.; Donaldson, K. Carbon nanotubes introduced into the abdominal cavity of mice show asbestos-like pathogenicity in a pilot study. Nat. Nanotechnol. 2008, 3, 423-428.

6. Nyholm, L.; Nyström, G.; Mihranyan, A.; Strømme, M. Toward flexible polymer and paper-based energy storage device. Adv. Mater. 2011, 23, 3751-3769. 
7. Razaq, A.; Nyholm, L.; Sjödin, M.; Strømme, M.; Mihranyan, A. Paper-based energy-storage devices comprising carbon fiber-reinforced polypyrrole-cladophora nanocellulose composite electrodes. Adv. Energy Mater. 2012, 4, 445-454.

8. Novak, P.; Muller, K.; Santhanam, K.S.V.; Haas, O. Conducting polymers for battery applications. Chem. Rev. 1997, 97, 207-281.

9. Shirakawa, H.; Lious, E.J.; MacDiarmid, A.G.; Chiang, C.K.; Heeger, A.J. Synthesis of electrically conducting organic polymers: Halogen derivatives of polyacetylene, $(\mathrm{CH})_{\mathrm{x}}$. J. Chem. Soc. Chem. Commun. 1977, 578-580.

10. MacDiarmid, A.G. Synthetic metals: A novel role for organic polymers (Nobel lecture). Angew. Chem. Int. Ed. 2001, 40, 2581-2590.

11. Li, C.; Peng, X.; Zhang, B.; Wang, B. An all-solid-state lithium/polyaniline rechargeable cell. J. Power Sources 1992, 39, 255-258.

12. Novak, P.; Inganas, O.; Bjorklund, R. Cycling behaviour of the polypyrrole-polyethylene oxide composite electrode. J. Power Sources 1987, 21, 17-24.

13. Yang, Y.; Lee, K.; Mielczarek, K.; Hu, W.; Zakhidov, A. Nanoimprint of dehydrated PEDOT:PSS for organic photovoltaics. Nanotechnology 2011, 22, 485301.

14. Wang, C.; Zheng, W.; Yue, Z.; Too, C.O.; Wallace, G.G. Buckled, stretchable polypyrrole electrodes for battery applications. Adv. Mater. 2011, 23, 3580-3584.

15. Wei, D.; Andrew, P.; Yang, H.; Jiang, J.; Ruan, W.; Han, D.; Niu, L.; Bower, C.; Ryhanen, T.; Rouvala, M.; Amaratunga, G.A.J.; Ivaska, A. Flexible solid state lithium batteries based on graphene inks. J. Mater. Chem. 2011, 21, 9762-9767.

16. Kil, E.H.; Ha, H.J.; Lee, S.Y. A facile approach to fabricate self-standing gel-polymer electrolytes for flexible lithium-ion batteries by exploitation of UV-cured trivalent/monovalent acrylate polymer matrices. Macromol. Chem. Phys. 2011, 212, 2217-2223.

17. Nystrom, G.; Razaq, A.; Stromme, M.; Nyholm, L.; Mihranyan, A. Ultrafast all-polymer paper-based batteries. Nano Lett. 2009, 9, 3635-3639.

18. Arbizzani, C.; Mastragostino, M. Polybithiophene as positive electrode in solid-state polyethylene oxide- $-\mathrm{LiClO}_{4}$ lithium rechargeable battery. Electrochim. Acta 1990, 35, 251-254.

(C) 2012 by the authors; licensee MDPI, Basel, Switzerland. This article is an open access article distributed under the terms and conditions of the Creative Commons Attribution license (http://creativecommons.org/licenses/by/3.0/). 